Historic, Archive Document

Do not assume content reflects current scientific knowledge, policies, or practices. 


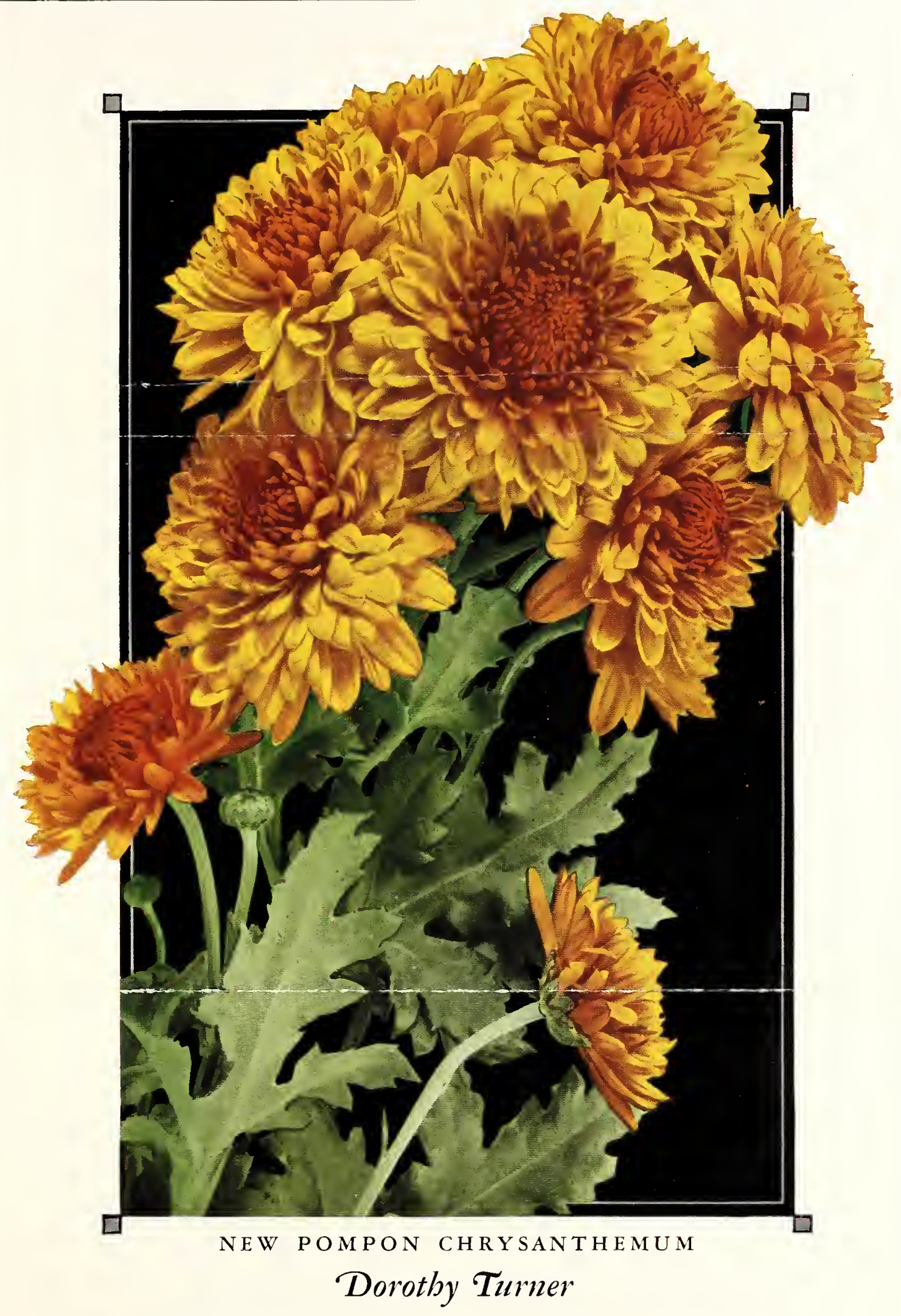

A. N. PIERSON, Inc., Cromwell, Conn. 


\section{NEW POMPON CHRYSANTHEMUM}

\section{Dorothy Turner}

I

T MAY be of interest to growcrs of Chrysanthemums to know that we specialize largely in Pompon Chrysanthemums as a seasonable cut-flower crop, devoting praetically our cntire glass area to these in season. Long ago we realizcd that ordinary Pompon Chrysanthemums would not pay, even as a seasonable crop, and that high quality was required to command the top market price. With this in vicw, we took up the origination of the better varieties. Today, 90 per cent of our Pompons are seedlings of our own origination, and all, we believc, are of supcrior quality. From these we have selected Dorothy Turner to disseminate this season, and in doing so we feel sure that it will at once take a prominent position in a class that is rapidly increasing in utility and popularity.

FIRST. It attains perfection just in time for the Thanksgiving season. It is the ideal Thanksgiving color, a lively combination of bronze and old-gold. The broad, overlapping petals are evenly shaded with rich old-gold, deepening to a chestnut-bronze at the center. It is difficult to describe the color accurately, but it is a blend that immediately attracts attention when shown in comparison with the frnest of existing kinds.

SECOND. Its habit of growth is about commercially perfect, branching strongly from the base and producing freely stems that are rigid and wiry, requiring very little support. Its average growth is 30 inches or higher. The foliage is rich, glossy green, of medium size, and has no tendency to discolor or drop at any stage; amply sufficient but not too heavy or dense to interfere with intensive bench cultivation-an important trait from a commercial standpoint. Further, it is of the correct type for pot-culture.

THIRD. The arrangement of the flowers is ideal, the individual blossoms bcing wcll placed along the stem. The flowers open more spontaneously than the average Pompon and are spaced sufficiently tight to make a perfect bunch or spray variety. It keeps well and is first-class in every respect from a market standpoint.

FOURTH. We know of no more productive Pompon. Growing in the solid bench, spaced 8 by 8 inches, our cut averaged slightly better than two good market bunches to threc plants, rating at least a bunch per one and one-half plants, and these eonsignments attaining a price of $\$ 1.50$ per bunch, and not less than $\$ 1.35$ on the New York market.

DOROTHY TURNER is the variety which, exhibited under number at the Annual Exhibition of the Chrysanthemum Socicty of America, held at Baltimore in 1927, captured the Silver Cup for the best seedling Pompon Chrysanthemum not disseminated. It was exhibited for us by A. N. Pierson, Inc., Cromwell, Conn., who, we are happy to say, will share its dissemination with us.

THE BRISTOL NURSERIES, INC. BRISTOL, CONN.

\section{And If Dorothy Turner Were Ours}

exelusively, we should keep it for the eut-flower trade to whieh we eater. But the Bristol Nurseries are to disseminate this seedling, and we have joined with them in this. We have growing for the market about 5,000 plants this year. It is a wonderful variety for the commercial grower. We aid in its dissemination because we like to handle the best, and Dorothy Turner is in that elass.

A. N. PIERSON, Inc., Cromwell, Conn.

\begin{tabular}{|c|c|}
\hline & PRICES \\
\hline Rooted Cuttings & . $\$ 15$ per $100, \$ 125$ per 1,000 \\
\hline From 2-inch Pots & . $\$ 20$ per $100, \$ 175$ per 1,000 \\
\hline
\end{tabular}

Orders will be filled in rotation. Rooted cuttings from February 1 on, and pot plants from March I on. These quotations are strictly wholesale. For retail orders, write Bristol Nurseries

\section{A. N.PIERSON, Inc, Cromwell, Conn.}

